\title{
ARTIFICIAL INTELLIGENCE APPLICATION AND ORGANIZATIONAL EFFICIENCY IN MANUFACTURING SECTOR IN RIVERS STATE
}

\author{
BEKURU Lemue John \& NWINYOKPUGI Patrick (Ph.D) \\ Department of Office and Information Management, \\ Faculty of Management Sciences, \\ Rivers State University, Port Harcourt, Nigeria.
}

\begin{abstract}
The study was to investigate the relationship between artificial intelligence application and organizational efficiency in manufacturing sector in Rivers State. A descriptive research survey design was used for the study. The sample of the study is six (6) operational managers from each of the twenty six (26) registered manufacturing companies in Rivers state by manufacturing association of Nigeria (MAN) Rivers state chapter. The population of the study is twenty six (26) registered operational manufacturing companies in Rivers state. The researcher distributed 156 questionnaires to the respondents. The method of data collection was through questionnaires. Data from the distributed questionnaires was further analyzed, using the Pearson Product Moment Correction Coefficient. The hypotheses of the study were tested using Pearson's product moment Correlation with aidof the statistical package for social science (SPSS). Findings revealed that, the predictor variable artificial intelligence and its dimension robotics, and electronic fund transfer have significant relationship with the measures of the criterion variable as innovation and cost reduction. Therefore, it was recommended among others that manufacturing sector should adopt the use of robot in their production process to bring about safety of their staff that might be working hazardous substances and in high risk sections of an organization.
\end{abstract}

Keywords: Artificial Intelligence, Organizational Efficiency, Robotics, Electronic Fund Transfer, Innovation, Cost Reduction. 


\section{INTRODUCTION}

Today, artificial intelligence application is a popular subject that is widely discussed in the technology and business world. Many experts and industry analysts argue that artificial intelligence or machine learning is the future-but if we look around, we are convinced that it's not the future, but it is already the present. The technology is in its initial phase and more and more companies are investing their resources in machine learning, indicating a robust growth in AIA products and apps in the near future (Hauser, 2018). Artificial intelligence application (AIA) is an area of computer science that emphasizes on the creation of intelligent machines that work and react like humans. Some of the activities they do are speech recognition, learning and planning problem-solving.

Artificial intelligence application is a branch of computer science that aims to create intelligent machines. It has become an essential part of the technology in the industry. Machine learning is also a core part of AIA. Artificial intelligence refers to systems designs to interpret data, use it to make decisions, solve problems and identify risk. Artificial intelligence application (AIA) is a branch of computer sciences that emphasizes on the development of intelligence machines, thinking and working like humans e.g. Speech recognition, problem-solving, learning and planning, decision-making visual perception (Smith, 2016). Learning AIA textbooks define the field as the study of "intelligent agents" any device that perceives its environment and takes actions that maximize its chance of successfully achieving its goals. AIA is a machine that mimics cognitive functions that humans associate with the human mind such as "learning and problem solving toward organizational efficiency.

Organizational Efficiency is an internal measure of performance for companies that shows how well the company converts inputs into outputs. The more the ratio of outputs to inputs approaches hundred percent, the better efficiency of the process will be in a simple term, it is doing things right and comes from proper harnessing of time, cost and efforts. For example, an employee can improve efficiency by developing a daily work schedule, avoiding personal distractions (Ubulom, Kayii \& Dambo, 2016; Rao \& Satoa, 2013). While discussing organizational efficiency, organizational effectiveness cannot be left out of the discussion because they are like Siamese twins (Hartnell, Ou \&Kinicki, 2011).

Organizational effectiveness is an internal measure of performance which indicates how well an organization fulfils the demands of various organizational stakeholders simply put, it is "doing the right thing". For example, in educational institutions, effectiveness is measured by teaching students what they need to know. Managers need to make sure that the services or products meet customers' expectations. When analysing a company's processes, effectiveness take procedure over efficiency (Low, 2000). These are the benefits relating to the efficiency and effectiveness. The two concepts efficiency and effectiveness overcomes the short-coming of using either of them. If managers focus on efficiency alone, they may jeopardized the competitiveness of their company.

For example, more focus on efficiency and ignores the contribution of the activity to customer value creation. Likewise, exclusive emphasis on effectiveness ignores the costeffectiveness of the activity improving productivity boosts competitiveness by lowering operational cost, using resources better, increasing market share and increasing profits (Chalmers, 2010). The harnessing of efficiency and effectiveness will give birth to productivity, which relate to the output of goods and services of the company to the inputs of 
the whole resources used in the production of goods and services. In other words, it measures how well a company transforms resources into products. Productivity is the combination of efficiency and effectiveness. This means that a company that only attains efficiency or effectiveness is either partially productive or not productive at all. To be productive a company needs to be efficient and effective at the same time (Jim, 2004).

Manufacturing and production efficiencies: Companies can increase their efficiency by running production processes well. When using state of the art technology and eliminating process that do not add value to their products, it will lead to lowering production costs.

Advanced technology often results in quicker production, better quality products and fewer product defects. Flexibility in production process allows companies to make adjustments where required so they can meet customer specification, companies can manage production and inventory efficiency by avoiding overproduction of products and overstocking of inventory (Susan, 2010).

In the manufacturing field prominent research has been carried out in a number of areas, including quality monitoring and production, scheduling, among others.

In a study, according to Kwantes and Boglarsky (2007) carried out an analysis of the production and rules in the way they are used in AI systems. The proposed new definition for productions refers to a large number of types of production that may be found in the literature on AI systems. This definition emphasises in the most general way those production component that are important both for theory and for practice and which for some reasons remain unnoticed by many researchers. These components are supplemented in a theoretical formalism.

In the area of manufacturing, Kahya (2008) proposed an artificial intelligence-based production scheduler. The production scheduler utilise a hybrid push/pull approach to scheduling and exploits the expert system technology in order to obtain satisfactory solutions. The scheduler is applied to a multi-stage production and inventory system, managed by make-to-order, with a large variety of incoming orders.

Another interesting research was carried out by Committee on Technology (2018) on tea quality prediction using a tin Okide-based electronic nose with an AI approach. In the research, the authors analysed using a metal oxide sensor (MOS) based electronic nose (EN) five tea samples with different qualities: normally drier mouth, drier mouth again over fired, well fermented normal dried in oven well-fermented over-fired in oven under-fermented normal fired in oven.

The study by Muller (2014) is an example in the respect. The focus is use of AI as a framework for understanding intuition. His research shows how the overlaps in Herbert Simon's work and especially his work on AI affected his view towards intuition. Herbert Simon made overlapping substantive contributions to the fields of economics, psychology, cognitive science, AI decision theory and organization theory.

Simon's work was motivated by the belief that the human mind, human thinking, decisionmaking in man, and human creativity need to be mysterious. It was after he helped create "thinking" machines that Simon came to understand human intuition as subconscious pattern recognition. In doing so he showed that intuition need not be associated with magic and 
mysticism, and that it is complementary with analytical thinking. However, a program written by a Simon led group according to this line of reasoning prove abortive.

In another work, Sainato (2015) reviews the shift from Alchemy to AI in western literature. The simplification underlying contemporary mythology of knowledge arises from fear of the power change that science entails leaving many people feeling confused and disempowered.

Kit emerges in the media, most often under the name of "Franken Stein" without any new discovery that appears to threaten social equilibrium (Seliger, \& Hartzog, 2015; Davidson, 2017), the authors contributed in two ways to the aims of the special issue on abstraction. The first is to show that there are compelling reasons motivating the use of abstraction on the purely computational realm of AI.

In recent time, the manufacturing sector in Nigeria had witnessed steady and rapid decrease in production mostly the manufacturing sector in Rivers state. This is not unconnected with the use of obsolete and outdated technological equipment in the sector. Preliminary investigation carried out by the researcher had shown that manufacturing sector in Rivers state suffered this experience, which $80 \%$ of the firms in the manufacturing sector are not producing to its expected capacity, comparing to their counterpart in other part of the world. Therefore, the researcher had decided to carry out an investigation to find out whether the implementation of artificial intelligence in the manufacturing sector in Rivers state will increase productivity more than profitability in the sector.

Though, most of the firms in the sector are indigenous owned firms which were not exposed to sophisticated technological equipment in their production process with, the aim of increasing production. Therefore, this study examined the influence of artificial intelligence application and organizational efficiency of the manufacturing sector in Rivers State. Specifically, the study sought to examine:

i. How robotics influences organizational efficiency in the manufacturing sector in Rivers State.

ii. How electronic fund transfer influences organizational efficiency in the manufacturing sector in Rivers State.

To achieve the target of the study, the following research questions were structured to guide the study and the hypotheses tested at 0.05 level of significance.

i. To what extent does robotics enhance organizational efficiency in the manufacturing sector in Rivers state?

ii. To what extent does Electronic Fund Transfer enhance organizational efficiency in the manufacturing sector in Rivers state?

H01: There is no significant relationship between Robotics and innovation in the manufacturing sector in Rivers state.

H0 $\mathbf{H}_{2}$ There is no significant relationship between Robotics and Cost Reduction in the manufacturing sector in Rivers state.

H03: There is no significant relationship between Electronic Fund Transfer and innovation in the manufacturing sector in Rivers state. 
H0 $\mathbf{H}_{4}$ There is no significant relationship between Electronic Fund Transfer and Cost Reduction in the manufacturing sector in Rivers state.

\section{METHODOLOGY}

\section{Philosophical foundation}

The philosophical foundation of this study artificial intelligence application and organisational efficiency in manufacturing sector in Rivers state is anchored on the philosophy of positivism. The philosophy of positivism is to investigate and proffer solutions to issues and phenomena which are notcleared.In this study, the researcher adopted descriptive research survey design. Descriptive studies are studies that involve the determination of relationship between two or more variables and use primary and secondary sources of data collection through the use of questionnaires. The design normally indicates the direction and magnitude of the relationship (Nwankwo, 2013).

The population of the study comprises the entire manufacturing companies operating in Rivers State. A survey by the manufacturers association of Nigeria, Rivers State branch revealed that 26 registered manufacturing companies operate in Rivers State.

This study adopted institutional units of analysis, therefore, only six principal officers (marketing, production, Human resources, safety and security, research and development, account and finance) were randomly drawn from all the twenty six (26) registered manufacturing companies operating in Rivers state. A total of 156 respondents were purposively selected for the study.

The research instrumentwas designed in four sections. The first section was designed to generate the demographic data of the respondents, the second section was structured to obtain data on the dimensions of artificial intelligence, thirdly, to elicit response and generate data on the measures of organizational efficiency. The dimensions of this variable are: robotics, electronic fund transfer, and the measures are innovation and cost reduction designed on a four points Likert scale with the weight: Strongly Agreed (SA) $=4$ points, Agreed (A) $=3$ points, Disagree $(\mathrm{D})=2$ points and Strongly Disagree $(\mathrm{SD})=1$ point.The initial test-retest scores of the sample were correlated using Pearson product moment correlation coefficient of 0.73.Data were analyze descriptively with mean and standard deviation while hypotheses tested using Pearson's Product Moment Correlation Coefficient.

\section{Results}

\subsubsection{Analysis of Research Questions}

In chapter one of this study, the researcher sought to ascertain the influence of the elements of artificial intelligence application and organizational efficiency of the manufacturing sector in Rivers State. The descriptive relationships between the components of artificial intelligence application and organizational efficiency are presented in this section. The descriptive statistics is presented to answer the research questions previously fixed in chapter one of this study. 
Research Question One: To what extent does robotics influence organizational efficiency of the manufacturing sector in Rivers State?

Table 1: Respondents' Mean Scores on the extent robotics influences organizational efficiency of the manufacturing sector in Rivers State

\begin{tabular}{|c|c|c|c|c|c|}
\hline $\mathrm{S} / \mathrm{NO}$ & STATEMENT & SUM & MEAN & S.D & REMARK \\
\hline 1 & $\begin{array}{l}\text { In manufacturing, robots automate repetitive } \\
\text { tasks, reduce margins of error to negligible } \\
\text { rates and enable human to focus on operation in } \\
\text { the workplace }\end{array}$ & 526 & 3.36 & 0.74 & \\
\hline 2 & $\begin{array}{l}\text { Robotics in manufacturing allows companies to } \\
\text { remain competitive globally, offering an } \\
\text { efficient, viable alternative to fulfil the skill gap } \\
\text { in the area }\end{array}$ & 504 & 3.23 & 0.89 & \\
\hline \multirow[t]{2}{*}{3} & $\begin{array}{l}\text { Robots can be programmed to operate } 24 / 7 \text { in } \\
\text { lights out situations for continuous production } \\
\text { without getting tired or bored. }\end{array}$ & 443 & 2.84 & 0.92 & \\
\hline & Grand Mean & & 3.29 & 0.81 & $\mathrm{HE}$ \\
\hline
\end{tabular}

Table 1 shows respondents' mean and standard deviation value; it was revealed that robots automate repetitive tasks, reduce margins of error to negligible rates and enable human to focus on operation in the workplace $3.23(0.89)$, robotics in manufacturing allows companies to remain competitive globally, offering an efficient, viable alternative to fulfil the skill gap in the area $3.23(0.89)$ and robots can be programmed to operate $24 / 7$ in lights out situations for continuous production without getting tired or bored with value $2.84(0.92)$. With a grand mean of 3.29 implies that robotics influences organizational efficiency of the manufacturing sector in Rivers State to a high extent.

Research Question Two: To what extent does Electronic Fund Transfer influence organizational efficiency of the manufacturing sector in Rivers State?

Table 2: Respondents' Mean Scores on the extent Electronic Fund Transfer influences organizational efficiency of the manufacturing sector in Rivers State

\begin{tabular}{|c|c|c|c|c|c|}
\hline $\mathrm{S} / \mathrm{NO}$ & STATEMENT & SUM & MEAN & S.D & REMARK \\
\hline 4 & $\begin{array}{l}\text { Electronic Fund transfer can make transactions } \\
\text { such as deposit, cash withdrawals, fund } \\
\text { transfers, or account information at any time } \\
\text { without the direct interaction with bank } \\
\text { representative. }\end{array}$ & 410 & 2.66 & 0.77 & \\
\hline 5 & $\begin{array}{l}\text { With electronic Fund transfer, you can do your } \\
\text { transactions } 24 / 7 \text { at the comfort of your } \\
\text { workplace. }\end{array}$ & 448 & 2.91 & 0.81 & \\
\hline \multirow[t]{2}{*}{6} & $\begin{array}{l}\text { The device had completely eliminated the era } \\
\text { of carrying bulk of money (physical cash) from } \\
\text { one place to another. }\end{array}$ & 447 & 2.90 & 0.91 & \\
\hline & Grand Mean & & 2.79 & 0.79 & ME \\
\hline
\end{tabular}


Table 2 shows respondents' mean and standard deviation values; it was revealed that electronic cash transfer can make transactions such as deposit, cash withdrawals, fund transfers, or account information at any time without the direct interaction with bank representative $2.66(0.77)$, electronic cash transfer, workers can do your transactions 24/7 at the comfort of your workplace $2.91(0.81)$ and electronic cash transfer had completely eliminated the era of carrying bulk of money (physical cash) from one place to another with value $2.84(0.92)$. With a grand mean of 2.79 implies that electronic cash transfer influences organizational efficiency of the manufacturing sector in Rivers State to a moderate extent.

\section{Test of Hypotheses}

\section{Decision Rule}

Significant/probability value $(\mathrm{Pv})<0.05$ (level of significance $=$ significant relationship.

Significant probability value $(\mathrm{Pv})>0.05$ (level of significant $=$ not significant relationship.

H0. There is no significant relationship between robotics and innovation of the manufacturing sector in Rivers State

Table 3: Relationship between Robotics and Innovation of the Manufacturing Sector in Rivers State

ROBOTICS INNOVATION

\begin{tabular}{llll}
\hline \multirow{2}{*}{ ROBOTICS } & \multicolumn{2}{l}{ Pearson Correlation 1 } & -.033 \\
& Sig. (2-tailed) & 154 & .688 \\
& $\mathrm{~N}$ & 154 \\
& Pearson Correlation & -.033 & 1 \\
INNOVATION & Sig. (2-tailed) & .688 & \\
& $\mathrm{~N}$ & 154 & 154 \\
\hline
\end{tabular}

Table 3 shows the result that the correlation between robotics and innovation of the manufacturing sector in Rivers State is -0.33 . For two-tailed test, the observed correlation between robotics and innovation has a significant level (sig 2-tailed) of 0.0688 is greater than the chosen Alpha level of 0.05. Therefore, the null hypothesis of no significant relationship between robotics and innovation of the manufacturing sector in Rivers State is retained. That is, there is indeed no statistical relationship $\mathrm{r}(152)=-0.33, \mathrm{P}>0.05$.

$\mathrm{HO}_{2}$ : There is no significant relationship between robotics and cost reduction of the manufacturing sector in Rivers State.

Table 4: Relationship between robotics and cost reduction of the Manufacturing Sector in Rivers State

\begin{tabular}{llll}
\hline & & Robotics & \multicolumn{1}{c}{ Cost Reduction } \\
\hline \multirow{3}{*}{ Robotics } & \multicolumn{1}{l}{ Pearson Correlation 1} & -.150 \\
& Sig. (2-tailed) & & .064 \\
Cost Reduction & $\mathrm{N}$ & 154 & 154 \\
& Pearson Correlation & -.150 & 1 \\
& Sig. (2-tailed) & .064 & \\
& $\mathrm{~N}$ & 154 & 154 \\
\hline
\end{tabular}


Table 4 shows the result that the correlation between robotics and cost reduction of the manufacturing sector in Rivers State is -.150. For two-tailed test, the observed correlation between robotics and cost reduction has a significant level (sig 2-tailed) of 0.64 is greater than the chosen Alpha level of 0.05. Therefore, the null hypothesis of no significant relationship between robotics and cost reduction of the manufacturing sector in Rivers State is retained. That is, there is indeed no statistical relationship $\mathrm{r}(152)=-0.64, \mathrm{P}>0.05$.

$\mathbf{H O}_{3}$ : There is no significant relationship between Electronic Fund Transfer and innovation of the manufacturing sector in Rivers State.

Table 5: Relationship between Electronic Fund Transfer and innovation of the Manufacturing Sector in Rivers State

\begin{tabular}{llll}
\hline & & EFT & Innovation \\
\hline EFT & Pearson & 1 & .018 \\
& Correlation & & \\
& Sig. (2-tailed) & & .829 \\
& $\mathrm{~N}$ & 154 & 154 \\
Innovation & Pearson & .018 & 1 \\
& Correlation & & \\
& Sig. (2-tailed) & .829 & \\
& $\mathrm{~N}$ & 154 & 154 \\
\hline
\end{tabular}

EFT-Electronic Fund Transfer

Table 5 shows the result that the correlation between electronic fund transfer and innovation of the manufacturing sector in Rivers State is.018. For two-tailed test, the observed correlation between electronic fund transfer and innovation has a significant level (sig 2tailed) of .829 is greater than the chosen Alpha level of 0.05. Therefore, the null hypothesis of no significant relationship between electronic fund transfer and innovation of the manufacturing sector in Rivers State is retained. That is, there is indeed no statistical relationship $\mathrm{r}(152)=-0.83, \mathrm{P}>0.05$.

$\mathrm{H0}_{4}$ : There is no significant relationship between Electronic Fund Transfer and cost reduction of the manufacturing sector in Rivers State

Table 6: Relationship between Electronic Fund Transfer and cost reduction of the Manufacturing Sector in Rivers State

\begin{tabular}{llll}
\hline & & EFT & Cost Reduction \\
\hline EFT & Pearson & 1 & -.009 \\
& Correlation & & \\
& Sig. (2-tailed) & & .914 \\
& $\mathrm{~N}$ & 154 & 154 \\
Cost & Pearson & -.009 & 1 \\
Reduction & Correlation & & \\
& Sig. (2-tailed) & .914 & \\
& $\mathrm{~N}$ & 154 & 154 \\
\hline
\end{tabular}

EFT-Electronic Fund Transfer 
Table 6 shows the result that the correlation between electronic fund transfer and Cost reduction of the manufacturing sector in Rivers State is-.009. For two-tailed test, the observed correlation between electronic fund transfer and production efficiency has a significant level (sig 2-tailed) of.914 is greater than the chosen Alpha level of 0.05. Therefore, the null hypothesis of no significant relationship between electronic fund transfer and.914 of the manufacturing sector in Rivers State is retained based on the statistical evidence. That is, there is indeed no statistical relationship $\mathrm{r}(152)=-0.914, \mathrm{P}>0.05$.

\section{Discussions of Findings}

This study uses descriptive and survey design method in investigating the relationship between artificial intelligence application and organizational efficiency in manufacturing sector in Rivers state, as well as the moderating role of technology. The findings revealed there is a positive and significant relationship between artificial intelligence application and organizational efficiency in manufacturing sector in Rivers state, using the Pearson correlation coefficient with point above 0.05 indicating that there is a significant relationship between artificial intelligence and organizational efficiency. These findings support the idea of Kwantes and Boglarsky (2007) who claim that the application of artificial intelligence in an organization will increase production, cost reduction which will amount to high profitability which will also bring about robust growth in the industry. Many experts and industrialists argued that AI is the further that they are expecting because of the huge benefit (Hintze, 2016). The study also revealed that artificial intelligence is categorized into weak and strong artificial intelligence. The weak artificial intelligence is the one that handled specific task, while strong artificial intelligence is the one that will handle multiple tasks, which is yet to come into existence. For now it is a fiction.

From research finding one; this is in agreement with the study conducted by Davidow and Malone (2014) that robot performs jobs that are traditionally done by human being and carry out repetitive tasks and it should be used in manufacturing sector and in an environment that is hazardous to human. Robot is also equipped with the sense of vision, touch, and ability to sense temperature; even some of the robots today are taking simple decision in an unstructured environment. Within the industry today robot had introduced the ideal of using machine to increase productivity and reduce the cost of production. The study also makes us to realize that there are three principles that guide the behaviour of robots and smart machines.

These principles are what guided robots in its operations. Therefore robotics will bring about organization efficiency in manufacturing sector in Rivers state.

Research finding two: This is concerned with electronic fund transfer, which according to research by Howcroft (2002) is the electronic way of transferring of funds from one bank account directly to another bank account without any paper money changing hands.

This is supported by the work of Balanchandher, Santha, Norhazlinand Rajendra (2001) which made us understand that electronic fund transfer had done so much good to the manufacturing sector and the entire society at large. Looking back to the era when workers were also paid by hand in cash from their various organizations and companies, how workers were attacked by arm-robbers during end of months and also those that are carrying money in bulk for business purposes. All these set of people mentioned above were all robbed during the period mentioned and other times of the season. And during this robbery time, lives were 
also wasted by the criminals to enable them go away with the cash, but the good news now is that you can stay at the comfort of your home or workplace and do your financial transaction without the presence of any bank representative, no stress or to endanger yourself. Workers are now receiving their salary even sleeping in the comfort of their bed and also perform any type of financial transaction at their comfort because of electronic fund transfer, it is a welcome development.

\section{Conclusion}

It was concluded that artificial intelligence had become the way forward for manufacturing sector in Rivers state, because its application had enhanced efficiency in the organization and will lead to high productivity and cost reduction which shall amount to high profitability.

The study concluded that robotics does not only increase productivity, but also save humans from working in temperate region like the production plant, which can cause injury to humans.

\section{Recommendations}

Based on the findings of the study, the following recommendations are made by the researcher.

i. Manufacturing sector should adopt the use of robot in their production process to bring about safety of their staff that might be working hazardous substances and in high risk sections of an organisation.

ii. Electronic Fund Transfer is an innovation that reduces cost. Therefore, manufacturing sector in Rivers state should begin to use it to ensure security of personnel and financial resources. 


\section{REFERENCES}

Alai, M., (2004). AI, scientific discovery and realism, Minds and Machines, Journal of Innovative Studies 14(1), 21-42

Balanchandher, K. G., Santha, V., Norhazlin I, \&Rajendra, P. (2001). Electronic Banking in Malasia: A Note on Evolution of Services and Customer Relations

Bostrom, N. (2014). Superintelligence: Paths, dangers, strategies. Oxford University Press

Chalmers, D., (2010). "The singularity: Philosophical Analysis." Journal of Consciousness Studies, 1(7) 7-65.

Committee on Technology (2016). Subcommittee on Machine Learning and Artificial Intelligence, "Preparing for the future of artificial intelligence," Washington, DC: Office of Science and Technology Policy.

Davidow, W. H., \& Malone, M., (2014). What happens to society when robots replace workers?" Harvard Business Review, series 13, 443-564.

Davidson, P., (November, 2017). Automation could kill 73 million U.S. jobs by 2030," USA Today. Retrieved from https://www.usatoday.com/story/money/2017/11/29/autom ation-could-kill-73-million-u-s-jobs-2030/899878001/.

Franz M.R (2003). The Electrical Restitution Curve Revisited: Steep or Flat Slope-Which is Better? Journal of cardiovascular electrophysiology, 12(10), 140-S147

Future of Life Institute (2018). Benefits \& risks of artificial intelligence. Retrieved fromhttps://futureoflife.org/background/benefits-risks-ofartificial-intelligence/.

Greenhouse, S., (September, 2016). Autonomous vehicles could cost America 5 million jobs. What should we do about it? Los Angeles Time. Retrieved from http://www.latimes.com/opinion/op-ed/laoe-greenhouse-driverless-job-loss20160922-snapstory.html.

Hartnell, C.A. Ou A.Y. \&Kinicki, A. (2011). Organizational culture and organizational effectiveness. A meta-Analytical investigation of competing values framework is theoretical suppositions. Journal of Hppliod psychology, 96 (4), 677-94 .doi:101037/90021987.

Hauser, L., (February, 2018). Artificial Intelligence, Internet Encyclopedia of Philosophy, http://www.iep.utm.edu/art-inte/\#

Hintze, A., (2016). Understanding the four types of AI, from reactive robots to self-aware beings," The Conversation, http://theconversation.com/understanding-the-fourtypesof-ai-from-reactive-robots-to-self-aware-beings-67616.

Jim Sterne (2017). Artificial intelligence for marketing practical applications: publisher; wiley. 
Joao-Pierre, R., "6 examples of AI in business intelligence applications," Techemergence, https://www.techemergence.com/ai-in-business-intelligenceapplications/. August 24, 2020

Kahya, E. (2008). The effects of job performance on effectiveness. International journal of industrial ergonomics 39(1), 96-104.doi10-1016/J.ergoh.2008.06.006.

Kwantes, C. T., \&Boglarsky C.A. (2007). Perceptions of organizational culture, leadership effectiveness, and personal effectiveness across six countries, Journal of International management, 2(13) 204-213 doi.10.1016/j.intman.2007.03.002.

Low J., (2000). The value creation index Journal of inteklkectuakl capital. Vol. 1, 155:3, P. 252-262, DOI10,1108/146930010377119

Muller, V. C., (2014). Risks of general artificial intelligence," Journal of Experimental \& Theoretical Artificial Intelligence, 26(3), 297-301.

Ngwakwe, C.C. (2017). Corporate health and safety disclosure and sales revenue growth. Journal of Accounting Management, 2(4), 121-133.

Nwankwo, O.C. (2013). A Practical guide to research writing. Port Harcourt Press.

Ovaska-Few, S., (2017). How artificial intelligence is changing accounting. Journal of Accountancy, 12(1), 121-134.

Rajat, R. Anand M. \& Ng, A.Y., (2009). Large-scale deep unsupervised learning using graphics processors. In proceedings of the $26^{\text {th }}$ Annual International Conference on machine learning ACM, PP. 873-880.

Rao S. \&Satoa K.J. (2013). An attendance monitoring system using biometrics Authentication. International Journal of Advanced Research in Computer Science, 5(4), 43-55).

Sainato, M., (2015). Stepen Hawking, Elon Musk, and Bill Gates warn about artificial intelligence," Observer, Retrieved from http://observer.com/2015/08/stephenhawking-elon-muskand-bill-gates-warn-about-artificial-intelligence/.

Seliger, E., \&Hartzog, W., (2015). The dangers of trusting robots: AI: The ultimate guide. Retrieved from BBC, http://www.bbc.com/future/story

Smith, R., (2017). IBM's Watson artificial intelligence project is probably a whole lot bigger than you ever imagined," The Motley Fool, https://www.fool.com/investing/2017/08/30/ibmwatson-everything-you-ever-wantedto-know.aspx. August 30, 2020

Ubulom, W.J Kayii, N.E \&Dambo B.I (2016). Information and Communication Technology and Business Studies Students' Academic Performance in Upper Basic Education in Tai Local Government Rivers State, Nigeria. International Journal of Innovative Social \& Science Education Research, 4(1), 1-7. 